\title{
Effect of inhaled tacrolimus on ischemia reperfusion injury in rat lung transplant model
}

\author{
Johanna Bayer, MD, ${ }^{a}$ Nitin A. Das, MD, ${ }^{a}$ Clinton E. Baisden, MD, ${ }^{a}$ Meenakshi Rani, PhD, ${ }^{b}$ \\ Daniel T. DeArmond, MD, ${ }^{\mathrm{a}}$ Jay I. Peters, MD, ${ }^{\mathrm{c}}$ and Scott B. Johnson, $\mathrm{MD}^{\mathrm{a}}$
}

\begin{abstract}
Objective: Systemic tacrolimus therapy has been shown to protect against lung ischemia-reperfusion injury in animal models. We sought to investigate on a functional and cellular level if inhaled nanoparticle tacrolimus administered to the donor lung before procurement could similarly attenuate ischemia-reperfusion injury after lung transplant.
\end{abstract}

\begin{abstract}
Methods: An isogenic orthotopic rat model of single left lung transplant was used. Donor animals were pretreated with inhaled tacrolimus (treatment group) or inhaled lactose (controls) before lung procurement. Lung grafts were subjected to 3 hours of cold ischemia followed by 4 hours of reperfusion after graft implantation. Recipient animal arterial blood gas measurement and isograft wet to dry weight ratios were obtained. Macrophage, neutrophil, and T-cell accumulation and activation in lung isografts, including $\gamma \delta$ T-cell, T-helper, and cytotoxic T-cell subtypes were analyzed by flow cytometry. Tacrolimus levels were measured in the lung isograft using liquid chromatography/mass spectrometry. Isograft cytokine levels were measured with commercial enzyme-linked immunosorbent assay and microbead array kits.
\end{abstract}

Results: Oxygenation in treatment group animals was significantly higher than in controls. The presence of macrophages, neutrophils, and all T-cell subtypes in the isografts as well as isograft levels of inflammatory cytokines were all less in the treatment group versus controls, although no single variable achieved statistical significance.

Conclusions: Inhaled nanoparticle tacrolimus treatment of lung donors is associated with an attenuation of ischemia-reperfusion injury on a functional and cellular level in lung transplant. (J Thorac Cardiovasc Surg 2013;146:1213-9)

Donor allograft ischemia-reperfusion injury (IRI) is an important source of morbidity and mortality after lung transplant. ${ }^{1}$ IRI is thought to play a central role in the development of primary graft dysfunction, an important source of morbidity and mortality in the first year following lung transplant affecting up to $10 \%$ to $25 \%$ of all lung transplant recipients. ${ }^{1}$ Furthermore a retrospective review of human lung transplant recipients has

From the Department of Cardiothoracic Surgery, ${ }^{a}$ Division of Trauma \& Emergency Surgery, ${ }^{\mathrm{b}}$ Department of Surgery, and Division of Pulmonology, ${ }^{\mathrm{c}}$ Department of Medicine, University of Texas Health Science Center in San Antonio, San Antonio, Tex.

This study was funded in part by a generous grant from the Institute for Integration of Medicine and Science, Clinical and Translational Science Award grant No. UL1RR025767.

Disclosures: The University of Texas at Austin owns the patent for inhaled tacrolimus nanoparticles, if the patent was licensed by the university, J.I.P. would receive remuneration. All other authors have nothing to disclose with regard to commercial support.

Read at the 93rd Annual Meeting of The American Association for Thoracic Surgery, Minneapolis, Minnesota, May 4-8, 2013.

Received for publication May 5, 2013; revisions received July 7, 2013; accepted for publication July 11, 2013; available ahead of print Sept 11, 2013.

Address for reprints: Johanna Bayer, MD, Department of Surgery, University of Texas Health Science Center in San Antonio, 7703 Floyd Curl Dr, San Antonio, TX 78229-3900 (E-mail: Bayer@uthscsa.edu).

$0022-5223 / \$ 36.00$

Copyright (c) 2013 by The American Association for Thoracic Surgery

http://dx.doi.org/10.1016/j.jtcvs.2013.07.030 identified an increased risk of developing chronic rejection (bronchiolitis obliterans syndrome) in patients who experienced IRI. $^{2}$

It has been shown that tacrolimus is able to attenuate IRI. It has been associated with an attenuation of IRI through decreased free radical production, inhibition of calcium-dependent pathways, and inhibition of nuclear factor $\kappa \mathrm{B} .{ }^{3}$ In a rat lung warm ischemia reperfusion model, pretreatment with systemically administered tacrolimus was associated with a decrease in IRI via a reduction in proinflammatory cytokine expression and neutrophil accumulation in the lung tissue. ${ }^{4}$ The potential downside of systemic treatment of the donor with tacrolimus before organ procurement includes nephrotoxicity at the doses required to achieve adequate tissue levels in the lung. However, the lung affords a unique route of administration via inhalation therapy. Recently, an inhaled nanoparticle formulation of tacrolimus was characterized in terms of its pharmacokinetics to provide high lung and low systemic tacrolimus levels, theoretically reducing the risk of nephrotoxicity of tacrolimus therapy. ${ }^{5} \mathrm{We}$ sought to determine if pretreatment of donor animals with this novel inhaled preparation of tacrolimus before organ procurement and subsequent transplantation into a recipient animal could attenuate IRI by functional and cellular analysis. 


\section{Abbreviations and Acronyms \\ $\mathrm{CD}=$ clusters of differentiation \\ IRI $=$ ischemia-reperfusion injury}

\section{MATERIAL AND METHODS \\ Animals}

Isogenic, orthotopic, left lung transplants were performed using male inbred Fischer rats (Charles River, Wilmington, Mass). The Institutional Animal Care and Use Committee of The University of Texas Health Science Center at San Antonio approved this animal research protocol (Institutional Animal Care and Use Committee protocol No. 11052x) and all animals received humane treatment in accordance with the Principles of Laboratory Animal Care formulated by the National Society for Medical Research and the Guide for the Care and Use of Laboratory Animals prepared by the National Academy of Sciences and published by the National Institutes of Health.

\section{Inhalation}

Nanoparticle tacrolimus was prepared by The University of Texas College of Pharmacy, Austin, Tex. Nebulized nanoparticle tacrolimus consisted of $12.8 \mathrm{mg}$ nanoparticle tacrolimus mixture $(6.4 \mathrm{mg}$ nanoparticle tacrolimus $+6.4 \mathrm{mg}$ lactose) dispersed in $6 \mathrm{~mL}$ normal saline by sonication for 3 minutes. Awake, spontaneously breathing donor animals in the treatment group $(n=6)$ received a 1-time dose of inhaled nebulized nanoparticle tacrolimus before graft procurement via a nose-only dosing chamber (AeroNeb Pro nebulizer; Aerogen, Galway, Ireland). Lactose solution was prepared by mixing $6.4 \mathrm{mg}$ lactose powder with $6 \mathrm{~mL}$ normal saline by agitation for 3 minutes. Control animals $(n=6)$ received nebulized lactose once before lung harvest in a manner identical to that described for treatment animals. The lungs from the donor animals in the treatment and control group underwent procurement within 1 hour of administration of the nanoparticle tacrolimus or nebulized lactulose.

\section{Donor Organ Procurement}

Donor rats were anesthetized using 3\% to $5 \%$ inhaled isoflurane (Halocarbon, River Edge, NJ) admixed with oxygen via tracheostomy on a small animal ventilator (Harvard Apparatus, Holliston, Mass) with a tidal volume of $10 \mathrm{~mL} / \mathrm{kg}$ and a respiratory rate of 60 to $80 \mathrm{bpm}$ with positive end expiratory pressure of $2 \mathrm{~cm}$ water. Heparin $1000 \mathrm{units} / \mathrm{kg}$ (APP Pharmaceuticals, Schaumburg, Ill) was administered intravenously through the penile vein or hepatic bed. Laparosternomy incision was performed. Lung preservation was performed with $20 \mathrm{~mL}$ Perfedex solution (Xvivo, Göteborg, Sweden) at $4{ }^{\circ} \mathrm{C}$ and $20 \mathrm{~cm}$ water perfusion pressure delivered via the pulmonary artery. The trachea was clamped after insufflation of the lung to 3 to $4 \mathrm{~cm}$ water pressure. After transfer of the excised heart-lung block to a frozen operating stage, the left pulmonary vein, artery, and left main bronchus were mounted with cuffs fashioned from 14-Ga angiocatheters (Becton Dickinson, Sandy, Utah). Lungs were preserved for a 3-hour period of cold ischemia in an inflated state submerged in Perfedex solution at $4^{\circ} \mathrm{C}$ after which they were transplanted into recipient animals.

\section{Transplantation}

Orthotopic left lung transplantation with modified cuff technique was performed as described by Mizuta and colleagues. ${ }^{6}$ Recipient rats were anesthetized as described above for donor animals via oro-tracheal intubation with a 14-Ga angiocatheter. Left lateral thoracotomy was performed and hilar structures clamped using microaneurysm clips (Yasargil; Aesculap, Center Valley, Pa). The donor pulmonary artery, vein, and bronchus were anastomosed to respective structures of the recipient using 6-0 silk ties. The recipient procedure was timed to achieve a total ischemic time of 3 hours in the donor lung. Thoracotomy incisions were closed using 3-0 Ethibond suture (Ethicon Inc, Somerville, NJ). The recipient animal was extubated after demonstrating spontaneous breathing and was recovered from anesthesia in a warm chamber attached to a $100 \%$ oxygen line.

\section{Experimental Endpoint and Sample Collection}

Recipient animals were allowed to recover from anesthesia and resume full activity followed by euthanasia timed to achieve 4 hours of reperfusion of the transplanted isograft.

At euthanasia, recipient animals were anesthetized and ventilated at settings as described above via tracheostomy. Laparosternomy incision was performed. Arterial blood gas analysis was performed by ascending aortic puncture after clamping the right lung hilum and hyperventilation (at 100 bpm) for 5 minutes. All rats were ventilated with inspired oxygen fraction of $100 \%$ oxygen at the time of the aortic puncture. Bronchoalveolar lavage was performed using $5 \mathrm{~mL}$ phosphate buffered saline. The left lung was flushed via the pulmonary artery using normal saline (Braun Medical Inc, Irvine, Calif) at $4{ }^{\circ} \mathrm{C}$ before left lung isograft excision. Samples for flow cytometry assay were collected and the segment employed for wet to dry ratio was weighed immediately. The remaining segments of lung tissue designated for measurement of cytokines and tacrolimus levels were frozen in liquid nitrogen. All samples for cytokine and tacrolimus levels were stored in $\mathrm{a}-80^{\circ} \mathrm{C}$ freezer until analysis.

A group of naive animals were euthanized in the same fashion as the recipient animals to obtain baseline parameters; these animals did not receive any treatment or underwent any procedures beside euthanasia under anesthesia. On these animals the same analysis was performed and the same samples collected as in the treatment and control group. The results for the naïve animals were not included, because the purpose of this study was to show the effect of inhaled tacrolimus on the IRI compared with the control group.

The overall studies design did not allow the personnel involved in the experimental part and the sample collection to be blinded, but all animals were treated in the same manner regardless of which group they belonged to following a strict protocol that was developed before starting the experiment. The cytokine analysis and the analysis of the tacrolimus levels were performed by independent laboratories workers of which where blinded to the study design and the collected samples.

\section{Arterial Blood Gas}

Arterial blood gas analysis was performed using an Optical ABG machine (OPTI CCA-TS analyzer; OPTI Medical Systems, Inc, Roswell, $\mathrm{Ga}$ ). Alveolar-arterial gradient was calculated using the arterial oxygen tension, arterial carbon dioxide tension, and the barometric pressure obtained from the arterial blood gas analysis via an online calculator (http://www.globalrph.com/aagrad.htm).

\section{Wet to Dry Weight Ratio}

For the wet to dry ratio the lung tissue was weighed immediately after euthanasia (wet weight) followed by drying in a humidity controlled incubator $\left(\mathrm{CO}_{2}\right.$ water jacketed incubator; Forma, Thermo-Scientific, Waltham, Mass) at $37.5^{\circ} \mathrm{C}$. After 48 hours the lung tissue was weighed again and the dry tissue weight obtained. The wet to dry ratio was calculated by dividing the wet weight from the dry weight.

\section{Flow Cytometry}

Left lung isograft tissue for flow cytometry analysis underwent digestion with $1 \mathrm{mg} / \mathrm{mL}$ collagenase and deoxyribonuclease (Sigma-Aldrich, St Louis, Mo) in RPMI 1640 medium (Invitrogen, Grand Island, NY) for 30 minutes, followed by filtering through a $70-\mu \mathrm{m}$ filter to achieve a single cell suspension. One million cells for each tested sample were transferred to fluorescence activated cell sorting tubes after cell counting with an automated cell counter (Countess; Invitrogen, Grand Island, NY). The cell 
TABLE 1. Antibody panel for flow cytometry analysis

\begin{tabular}{|c|c|c|c|c|c|}
\hline Antibodies & Flurochrome & Concentration & Clone & Source & Isotype \\
\hline \multicolumn{6}{|l|}{ Panel A } \\
\hline Anti-rat CD11b/c & APC & $0.2 \mathrm{mg} / \mathrm{mL}$ & OX -42 & BioLegend* & Mouse $\operatorname{IgG} 2 \mathrm{a}, \kappa$ \\
\hline Anti-rat CD3 & FITC & $0.5 \mathrm{mg} / \mathrm{mL}$ & G4.18 & eBioscience $\dagger$ & Mouse $\operatorname{IgG} 3, \kappa$ \\
\hline Anti-rat TCR $\gamma / \delta$ & PE & $0.2 \mathrm{mg} / \mathrm{mL}$ & V65 & BioLegend & Mouse $\operatorname{IgG} 1, \kappa$ \\
\hline Anti-rat CD25 & Per CP-eFluorł 710 & $0.2 \mathrm{mg} / \mathrm{mL}$ & OX 39 & eBioscience & Mouse IgG1 \\
\hline \multicolumn{6}{|l|}{ Panel B } \\
\hline Anti-rat CD3 & PE & $0.2 \mathrm{mg} / \mathrm{mL}$ & G4.18 & eBioscience & Mouse IgG3, $\kappa$ \\
\hline Anti-rat CD4 & FITC & $0.5 \mathrm{mg} / \mathrm{mL}$ & OX 35 & eBioscience & Mouse IgG2a \\
\hline Anti-rat CD8a & APC & $0.2 \mathrm{mg} / \mathrm{mL}$ & G28 & BioLegend & Mouse IgG2a, $\kappa$ \\
\hline Anti-rat CD25 & Per CP-eFluor $\ddagger 710$ & $0.2 \mathrm{mg} / \mathrm{mL}$ & OX 39 & eBioscience & Mouse IgG1 \\
\hline
\end{tabular}

$C D$, Clusters of differentiation; $A P C$, allophycocyanin; $I g G$, immunoglobulin G; TCR, T-cell receptor; PE, phycoerythin; FITC, fluorescein isothiocyanate. *BioLegend, San Diego, Calif. †eBioscience, San Diego, Calif. $\ddagger$ Per CP-eFluor, emits at $710 \mathrm{~nm}$ and is excited with the blue laser (488 nm).

solutions were stained with anti-rat antibodies for cluster of differentiation (CD) molecules CD3, CD45, CD8, CD4, CD 25, $\gamma \delta$ T-cell receptor, and $\mathrm{CD} 11 \mathrm{~b}$ antibodies. Two different panels were used (see Table 1).

Flow cytometry was performed using a LSR II flow cytometer (Becton Dickinson, Franklin Lakes, NJ); analysis was performed by the institutional core flow cytometry facility. For each sample 30,000 events were counted. The data was analyzed using FACSDiva software (version 6.1.3; BD Biosciences, San Jose, Calif).

\section{Tacrolimus Level}

Tacrolimus levels were quantified in the isografts of treatment group animals using high-performance liquid chromatography with tandem mass spectroscopy detection in the institutional Mass Spectrometry Core Facility.

\section{Cytokine Assay}

Liquid-nitrogen frozen lung tissue (0.1-0.4 g) was thawed on ice and homogenized in $0.4 \mathrm{~mL}$ extraction reagent (T-PER; Thermo Fisher Scientific Inc, Rockford, Ill) with 1 tablet/10 mL Complete Mini Protease Inhibitor Cocktail (Roche Diagnostics, Mannheim, Germany), and supernatants collected following centrifugation. Interleukin (IL)-1 $\alpha$, IL-1 $\beta$, IL-2, IL-4, IL-6, IL-10, IL-12 (p40/p70), granulocyte-macrophage colonystimulating-factor, interferon- $\gamma$, and tumor necrosis factor- $\alpha$ were quantified by microbead array using a rat 10-plex panel (Invitrogen, Camarillo, Calif) analyzed on a Flexmap 3D multiplexing platform (Luminex, Austin, Tex). Rat IL-17 and IL-18 were quantified using rat IL-17A (eBioscience, San Diego, Calif) and IL-18 (Invitrogen, Grand Island, NY) enzyme-linked immunosorbent assays according to the manufacturers' instructions.

\section{Statistical Analysis}

All animals included in the analysis had survived to the experimental endpoints and had complete set of data for various assays.

Treatment groups (treated, control, and naïve) were contrasted on the mean using analysis of variance with Tukey correction for pairwise comparisons. Continuously distributed outcomes were summarized with the mean \pm standard deviation (SD). The naïve group is not included in the results section and all $P$ values represent the Tukey corrected comparison of the treated and control groups. For certain variables, indicated in Table 1, data were transformed using the natural log before analysis. All values are shown in original units. All analyses were performed using R 2.14.2 (The R Foundation for Statistical Computing; www.r-project.org).

\section{RESULTS}

\section{Cohort Characteristics and Operative Times}

The mean $\pm \mathrm{SD}$ weight of the donor animals in the treatment and control groups were $262.8 \pm 10.9 \mathrm{~g}$ and
$270.7 \pm 21.3 \mathrm{~g}$, respectively $(P=.69)$ and of recipient animals in treatment and control groups were $265.5 \pm 12.5 \mathrm{~g}$ and $272.8 \pm 16.7 \mathrm{~g}$, respectively $(P=.42)$. The mean time from treatment to isograft procurement was $26.7 \pm 1.6 \mathrm{mi}-$ nutes in the treatment group versus $27.2 \pm 7.3$ minutes in the control group $(P=.87)$. Total ischemia time in the treatment versus control groups were $180 \pm 3.4$ minutes and $184.7 \pm 8.8$ minutes, respectively $(P=.25)$. The reperfusion time for the treatment group was $237.2 \pm 4.1$ minutes and for controls was $235.8 \pm 6.1$ minutes $(P=.66)$.

\section{Arterial Blood Gas and Alveolar-Arterial Gradient}

The mean arterial oxygen tension value obtained from treatment group recipient animals (344.8 $\pm 235.1 \mathrm{~mm}$ $\mathrm{Hg})$ was significantly higher than controls $(61.3 \pm 21.4$ $\mathrm{mm} \mathrm{Hg})(P=.01)$. The mean alveolar to arterial oxygen gradient in the treatment group was significantly less than controls $(231.8 \pm 214.2 \mathrm{~mm} \mathrm{Hg}$ vs $502.8 \pm 35.8 \mathrm{~mm} \mathrm{Hg}$; $P=.01)$.

\section{Wet to Dry Ratio}

No significant difference in wet to dry weight ratio between treatment animals (12.5 \pm 1$)$ and controls $(11 \pm 1.7)$ was noted $(P=.99)$.

\section{Flow Cytometry in Isograft Lung Tissue}

$\mathrm{CD} 11 \mathrm{~b} / \mathrm{c}$ expressing cells were divided by scatter plot into 2 distinct cell populations based on their cell complexity (side scatter): CD11b/c low cells represent structurally less complex cells and are consistent with macrophages/monocytes and $\mathrm{CD} 11 \mathrm{~b} / \mathrm{c}$ high cells representing structural more complex cells, like granulocytes that include the neutrophil cell population (Figure 1). ${ }^{7}$

Flow cytometric analysis of the presence of inflammatory/immune cell subgroups in the lung isograft tissue showed a decrease in every measured cell type in treatment animals versus controls as well as in total cells per gram of lung tissue; however, none of these individual variables achieved statistical significance (Table 2). 


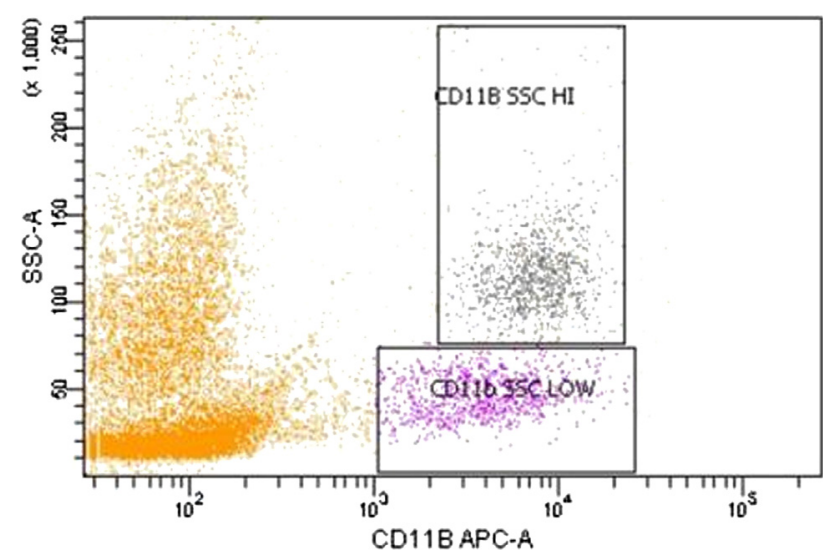

FIGURE 1. Flow cytometry scatter plot showing separation of the two $\mathrm{CD} 11 \mathrm{~b}$ cell populations by side scatter. $\mathrm{CD} 11 \mathrm{~b}$ high cell population (granulocytes/neutophils). CD11b low cell population ( monocytes/macrophages).

\section{Tacrolimus Levels}

The mean tacrolimus level in the lung isografts of treatment group animals after 3 hours of cold ischemia and before transplantation was $877.98 \pm 174.36 \mathrm{pg} / \mathrm{mg}$. After 4 hours of reperfusion the tacrolimus level in the lung tissue dropped to $34.58 \pm 6.2 \mathrm{pg} / \mathrm{mg}$.

When the tacrolimus levels were compared with the arterial oxygen tension levels, it was noted that the animals with the highest arterial oxygen tension levels also had the highest level of tacrolimus in the donor lung tissue before transplantation. The opposite observation was made for the neutrophil population (CD11b/c high positive cells) found on flow cytometry, the animals with the highest neutrophil count in the lung tissue had the lowest tacrolimus levels. (See Figure 2.)

\section{Cytokine and Chemoattractant Levels}

None of the isograft tissue levels of cytokines demonstrated a statistically significant difference between treatment and controls animals (Table 3). However, focusing on the proinflammatory cytokines (IL-1a, IL-1b, IL-2,

TABLE 2. Flow cytometry results

\begin{tabular}{lccc}
\hline Flow cytometry antibodies & $\begin{array}{c}\text { Control } \\
(\mathbf{n}=\mathbf{6})\end{array}$ & $\begin{array}{c}\text { Treatment } \\
(\mathbf{n}=\mathbf{6})\end{array}$ & $\boldsymbol{P}$ value \\
\hline CD11b/c low (macrophages) & $111.6 \pm 31.4$ & $85.1 \pm 41.6$ & .54 \\
CD11b high (neutrophils) & $139.9 \pm 42.9$ & $117.2 \pm 50.5$ & .58 \\
CD3 (all T-cells) & $217.3 \pm 126.4$ & $159.1 \pm 89.6$ & .65 \\
CD4 (helper T-cells) & $392.9 \pm 137.5$ & $308.7 \pm 117.8$ & .44 \\
CD8 (cytotoxic T-cells) & $173.9 \pm 43.4$ & $139.2 \pm 52.4$ & .39 \\
CD4/CD25 (regulatory & $63.7 \pm 26.3$ & $40.7 \pm 12.1$ & .26 \\
$\quad$ T-cells) & & & \\
CD3 / $\gamma \delta$ TCR ( $\gamma \delta$ T-cells) & $27.5 \pm 10.4$ & $22.4 \pm 5.5$ & .55 \\
Cells/g tissue & $60.2 \pm 16.5$ & $47.6 \pm 16.9$ & .35 \\
\hline D
\end{tabular}

Data are presented as mean \pm standard deviation $\times 10^{6} / \mathrm{g}$ lung tissue. $C D$, Clusters of differentiation; $T C R$, T-cell receptor.
IL-6, and IL-18), a downward trend in the treatment group versus controls was noted (Table 3 ). None of the isograft levels of chemoattractants demonstrated a statistically significant difference between treatment group and controls (Table 3).

\section{DISCUSSION}

Donor lung ischemia due to blood-supply interruption at the time of graft procurement results in the loss of mechanotransduction in the capillaries and arterioles of the donor lung which in turn leads to the generation of reactive oxygen species and cytokines through the activation of donor macrophages and endothelial cells, priming the donor lung tissue for injury upon reperfusion. As reperfusion occurs after implantation of the graft into the recipient, cytokines and reactive oxygen species are released into the recipient circulation and the entry of activated neutrophils from the recipient into the donor lung facilitated by upregulated nitric oxide signaling leads to direct vascular damage. Increased pulmonary vascular resistance and permeability within the donor lung ensue with the development of the clinical picture of pulmonary edema, worsening oxygenation, and decreased lung compliance, ${ }^{8,9}$

A growing body of literature has highlighted common pathways between IRI and rejection related to the fundamentally inflammatory/immune-mediated nature of IRI. In the setting of transplantation the reperfusion phase of IRI represents the first contact between the recipient inflammatory/immune system and donor tissue damaged by an ischemic insult, setting the stage for the subsequent development of graft rejection. The association of IRI with an increased risk of acute and chronic rejection may be related to an increased scope of donor epitope display to the recipient immune system due to cellular injury which results in a more differentiated and pronounced recipient versus donor immune response. ${ }^{2,10}$ A link between IRI and rejection suggests that immunosuppressive medications may represent a possible treatment avenue in IRI.

In prior studies, treatment of animals with systemic immunosuppression before submitting the lung to ischemia and reperfusion resulted in an attenuation of IRI. ${ }^{4}$ However, an important limitation of translating this strategy to human donors is the risk of nephrotoxicity due to the high systemic doses of tacrolimus required to achieve therapeutic drug levels in the lung graft with the potential of compromising the quality of donor renal allografts. This limitation may be overcome through the use of inhaled immunosuppressant therapy in donors; the inhalational route has been shown to provide high lung levels of immunosuppressant with low systemic absorption using a nanoparticle drug formulation. ${ }^{5}$ This has the potential not to interfere with other organ procurement teams and their organ harvests.

The purpose of this study was to evaluate early changes in the IRI and the effect of inhaled nanoparticle tacrolimus on 
$\mathrm{PaO}_{2}$ level vs Tacrolimus level

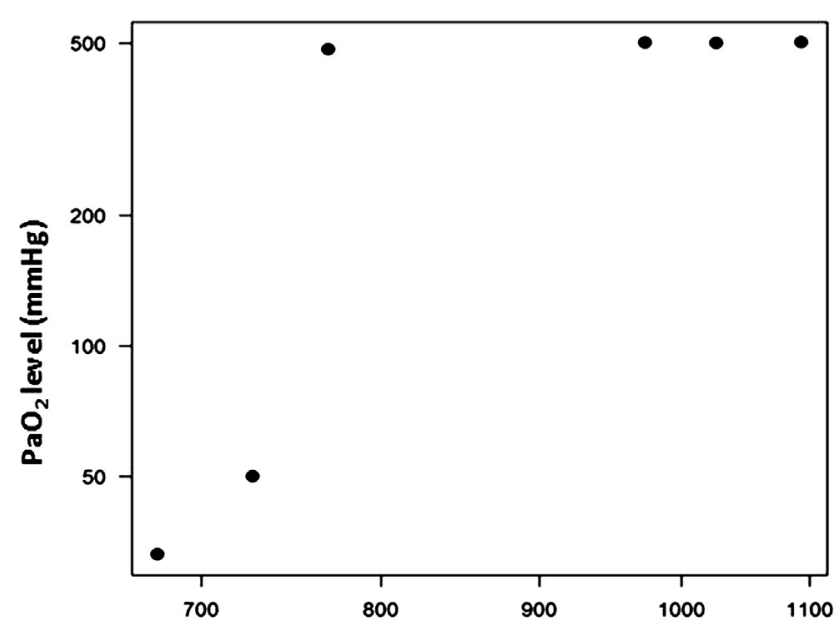

A

Tacrolimus level (pg/mg)

\section{11b/c High + Cells vs Tacrolimus level}

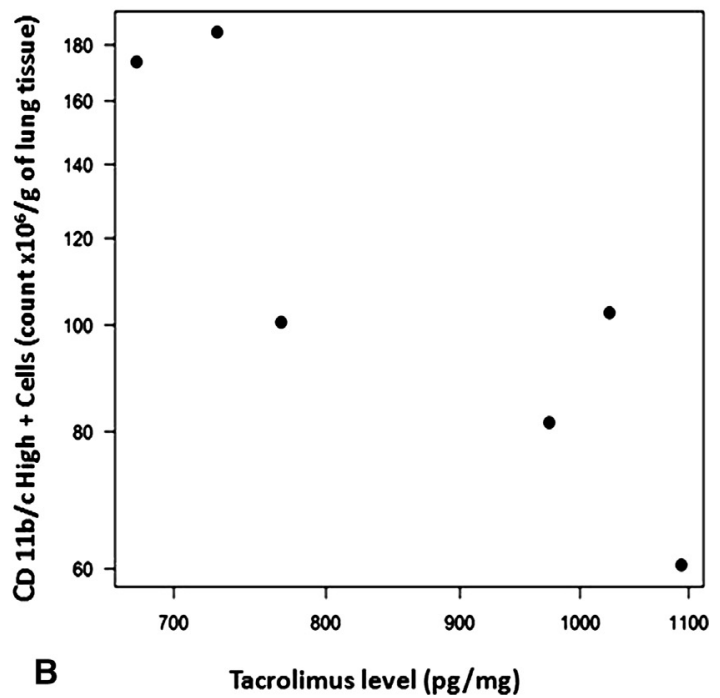

FIGURE 2. A, Oxygen tension $\left(\mathrm{PO}_{2}\right)$ level plotted against tacrolimus levels in the lung tissue measures after 3 hours of ischemia. B, Clusters of differentiation (CD)11b high cells (neutrophils) plotted against tacrolimus levels in the lung tissue after 3 hours of ischemia.

these, therefore 4 hours of reperfusion time point was chosen. The literature supports that within the first few hours after reperfusion there is an upregulation of cytokine expression and influx of inflammatory cells into the lung. ${ }^{7,11-14}$ In our study numerous inflammatory cytokines (Table 3) and all examined cellular elements (Table 2)

TABLE 3. Results for cytokines and chemoattractants

\begin{tabular}{lccc}
\hline \multicolumn{1}{c}{ Variable } & Control $(\mathbf{n}=\mathbf{6})$ & Treatment $(\mathbf{n}=\mathbf{6})$ & $\boldsymbol{P}$ value \\
\hline Cytokines & & & \\
IL-1a & $166.6 \pm 107$ & $87.7 \pm 33.6$ & .21 \\
IL-1b & $152.4 \pm 62.2$ & $95.7 \pm 36.6$ & .16 \\
IL-2 & $10.8 \pm 5.3$ & $8.8 \pm 2.8$ & .8 \\
IL-4 & $25.9 \pm 10.6$ & $22.2 \pm 10.1$ & .81 \\
IL-5 & $9.1 \pm 2.5$ & $11.4 \pm 3.7$ & .61 \\
IL-6 & $181.7 \pm 99.7$ & $112.6 \pm 91.3$ & .26 \\
IL-10 & $8.1 \pm 4.7$ & $5.8 \pm 4.2$ & .42 \\
IL-17A & $4.8 \pm 0.8$ & $5.2 \pm 0$ & .51 \\
IL-18 & $480.2 \pm 117.5$ & $368.3 \pm 103.3$ & .2 \\
IFN $\gamma$ & $9.5 \pm 2.1$ & $10.3 \pm 0$ & .51 \\
TNF $\alpha$ & $4.1 \pm 2.2$ & $2.2 \pm 1$ & .15 \\
Chemoattractants & & & \\
MIP-1a & $140.8 \pm 62.8$ & $101.9 \pm 30.1$ & .56 \\
MIP-2 & $577.3 \pm 311.8$ & $568.3 \pm 211.8$ & .93 \\
MCP-1 & $185.9 \pm 89.4$ & $136.9 \pm 81$ & .46 \\
IP-10 & $41.6 \pm 22$ & $31 \pm 10$ & .5 \\
GRO/KC & $2094.7 \pm 1389.5$ & $1616.8 \pm 735.5$ & .94 \\
Fractalkine & $92.7 \pm 29.3$ & $79.8 \pm 17.3$ & .7 \\
RANTES & $565.6 \pm 72.9$ & $578.2 \pm 137.7$ & 1.0 \\
\hline
\end{tabular}

Data are presented as mean \pm standard deviation. $I L$, Interleukin; IFN, interferon; $T N F$, tumor necrosis factor; $M I P$, macrophage inflammatory protein; $M C P$, monocyte chemoattractant protein; $I P$, interferon gamma-induced protein; $G R O / K C$, human growth regulated oncogene/keratinocyte chemoattactant; RANTES, Regulated on Activation Normal T cell Expressed and Secreted. were decreased in the transplanted lung of treatment animals compared to controls, but none were statistically significantly different. This may be a limitation of the reperfusion endpoint chosen in this study. Other studies have suggested that influx of inflammatory cells progressively increases after 4 hours of reperfusion over the next 24 hours. ${ }^{12}$ Most of studies evaluating IRI use a warm ischemia model or longer ischemia time, which could lead to a greater insult during the period of ischemia and a greater reperfusion injury. Possibly by choosing a longer ischemia time a greater ischemic insult could have been inflicted during this study, leading to a greater reperfusion injury with increased influx of lymphocytes and release of inflammatory cytokines, which could have lead to show a greater difference in the cellular and cytokine analysis between treatment and control group.

Even though significant changes in the oxygenation of the treatment and control group were found, no difference in the wet to dry ratio between the groups were noted. The wet to dry ratio is a simple way to gravimetrically assess pulmonary edema. Limitations of this method are: blood inclusion and extravasated protein can falsely increase the ratio, evaporative losses and spontaneous respiration versus mechanical ventilation can affect the ratio, regional heterogeneity of edema cannot be assessed, and hydrostatic edema and increased vascular permeability cannot be distinguished. ${ }^{15}$ In this study this approach was chosen over other methods to measure pulmonary edema (eg, permeability index), because this is an easy way to assess pulmonary edema without sacrificing the majority of lung tissue making it unavailable for further analyses, recognizing its limitations. In addition performing bronchoalveolar lavage during the necropsy might have affected 
the amount of water that had accumulated in the lung tissue therefore affecting the wet to dry weight ratio.

Other studies using a warm ischemia model in rats, administering tacrolimus either systemically or endotracheally were able to show attenuation of the ischemia reperfusion injury with decreased amount of neutrophil accumulation and inflammatory cytokine production. The proposed underlying mechanism from these authors was a reduction of nuclear factor $\mathrm{kB}$ activation by tacrolimus. ${ }^{4,16}$ Main limitation of their study was the use of a warm ischemia model, in contrast to our study, which used an orthotopic lung transplant model with cold ischemia, mimicking the clinical scenario of lung transplantation more closely. Nuclear factor $\mathrm{kB}$ activation is an early event in the inflammatory cascade of the IRI, which might not be the only way in which tacrolimus might affect the IRI. The main mechanism of action for which tacrolimus is known for, is the IL-2 inhibition. ${ }^{3}$ In this study a decrease in IL-2 production was noted in the treatment group compared with the control group, but this was not significant. Further this study did not investigate the mechanism, through which inhaled tacrolimus affect the IRI, nor did it look at the long-term effect of tacrolimus on the ischemia reperfusion injury, but this could be grounds for other studies in the future.

One main limitation of this study was the small samples sizes employed. Despite the observation of a significant difference in oxygenation between treatment and control groups, the study was not adequately powered to identify statistically significant differences in cytokine concentration or inflammatory/immune cell presence in the lung tissue of the 2 cohorts. This limited the conclusions that could be drawn about the mechanism of action of the drug in attenuating IRI.

Another important limitation of this study related to the inhaled drug delivery system employed. Drug delivery to the distal airways and alveoli required passage across the upper airways of awake, spontaneously breathing animals, which undoubtedly led to some drug loss to the upper airways or even externally to the experimental animal. In two of the six treatment animals this system failed to deliver sufficient drug to the alveoli, resulting in low isograft tissue levels of drug, which in turn was associated with decreased oxygenation and increased neutrophil presence in the isograft. In human lung donors, these limitations should theoretically not apply in that all human lung donors are supported with mechanical ventilation via some sort of endotracheal airway allowing direct access to the distal airways for more accurate drug delivery. Mc Courtie and colleagues ${ }^{17}$ found in their study assessing ischemia reperfusion injury in the rat lung, that only high dose systemically administered tacrolimus, but not low-dose tacrolimus reduced lung injury and activation of nuclear factor $\kappa \mathrm{B}$. This suggests that a certain threshold of tacrolimus in the lung tissue must be reached for the drug to assert its beneficial effects on the inflammatory cascade and attenuate the ischemia reperfusion injury. It is possibly that the 2 animals in this study with the low tacrolimus levels did not show an improvement in the ischemia reperfusion injury because the drug did not reach the required tissue threshold concentration.

In our study, pretreatment of donor animals with inhaled nanoparticle tacrolimus before organ procurement and transplantation into recipient animals significantly attenuated the adverse effects of IRI on isograft gas exchange with the treatment group demonstrating markedly higher arterial oxygen tension levels and diminished alveolararterial oxygen gradients compared with controls, as long as a threshold of drug concentration was reached. This attenuation of IRI by inhaled nanoparticle tacrolimus appeared to be related directly to the immunosuppressant/ anti-inflammatoty property of tacrolimus in that for treatment animals a consistent decrease in cytokine expression was observed compared with controls, although no individual cytokine expression decrease achieved statistical significance. Additionally, a consistent decrease in the presence of inflammatory/immune cellular elements in the lung tissue of treatment animals was observed despite not being statistically significant.

\section{CONCLUSIONS}

These findings taken as a whole suggest that inhaled nanoparticle tacrolimus therapy, through a local immunosuppressive/anti-inflammatory effect, may provide a means of mitigating IRI in lung transplantation.

The authors thank Robert Williams III, PhD, and Alan Watts, $\mathrm{PhD}$, from the School of Pharmacy at the University of Texas at Austin for preparing and generously donating the nanoparticle tacrolimus used for these experiments. The authors also thank the University of Texas Health Science Center in San Antonio Department of Epidemiology and Biostatistics and in particular Benjamin R. Ehler for performing the statistical analysis and support with the manuscript; the Core for Advanced Translational Technologies at University of Texas Health Science Center in San Antonio and Carolina B. Livi, PhD, for Luminex service to perform cytokine measurements; and the Biological Psychiatry Analytical Laboratory and Dr Martin Javors for help with measurement of the tacrolimus levels.

\section{References}

1. Lee JC, Christie JD. Primary graft dysfunction. Clin Chest Med. 2011;32:279-93.

2. Fiser SM, Tribble CG, Long SM, Kaza AK, Kern JA, Jones DR, et al. Ischemiareperfusion injury after lung transplantation increases risk of late bronchiolitis obliterans syndrome. Ann Thorac Surg. 2002;73:1041-7; discussion 1047-8.

3. St Peter SD, Moss AA, Mulligan DC. Effects of tacrolimus on ischemiareperfusion injury. Liver Transpl. 2003;9:105-16.

4. Krishnadasan B, Naidu B, Rosengart M, Farr AL, Verrier ED, Mulligan MS, et al. Decreased lung ischemia-reperfusion injury in rats after preoperative administration of cyclosporine and tacrolimus. J Thorac Cardiovasc Surg. 2002;123: 756-67. 
5. Watts AB, Cline AM, Saad AR, Johnson SB, Peters JI, Williams RO III. Characterization and pharmacokinetic analysis of tacrolimus dispersion for nebulization in a lung transplanted rodent model. Int J Pharm. 2010;384:46-52.

6. Mizuta T, Kawaguchi A, Nakahara K, Kawashima Y. Simplified rat lung transplantation using a cuff technique. Transplant Proc. 1989;21:2601-2.

7. Eppinger MJ, Jones ML, Deeb GM, Bolling SF, Ward PA. Pattern of injury and the role of neutrophils in reperfusion injury of rat lung. J Surg Res. 1995;58:713-8.

8. Den Hengst WA, Gielis JF, Lin JY, Van Schil PE, De Windt LJ, Moens AL. Lung ischemia-reperfusion injury: a molecular and clinical view on a complex pathophysiological process. Am J Physiol Heart Circ Physiol. 2010;299:H1283-99.

9. De Perrot M, Liu M, Waddell TK, Keshavjee S. Ischemia-reperfusion-induced lung injury. Am J Respir Crit Care Med. 2003;167:490-511.

10. Serrick C, Giaid A, Reis A, Shennib H. Prolonged ischemia is associated with more pronounced rejection in the lung allograft. Ann Thorac Surg. 1997;63:202-8.

11. Fiser SM, Tribble CG, Long SM, et al. Lung transplant reperfusion injury involves pulmonary macrophages and circulating leukocytes in a biphasic response. J Thorac Cardiovasc Surg. 2001;121:1069-75.

12. Adoumie R, Serrick C, Giaid A, Shennib H. Early cellular events in the lung allograft. Ann Thorac Surg. 1992;54:1071-6; discussion 1076-7.

13. Krishnadasan B, Naidu BV, Byrne K, Fraga C, Verrier ED, Mulligan MS. The role of proinflammatory cytokines in lung ischemia-reperfusion injury. $J$ Thorac Cardiovasc Surg. 2003;125:261-72.

14. De Perrot M, Young K, Imai Y, Liu M, Waddell TK, Fischer S, et al. Recipient $\mathrm{T}$ cells mediate reperfusion injury after lung transplantation in the rat. J Immunol. 2003; 171:4995-5002

15. Parker JC, Townsley MI. Evaluation of lung injury in rats and mice. Am J Physiol Lung Cell Mol Physiol. 2004;286:L231-46.

16. Woolley SM, Farivar AS, Naidu BV, Rosengart M, Thomas R, Fraga C, et al. Endotracheal calcineurin inhibition ameliorates injury in an experimental model of lung ischemia-reperfusion. J Thorac Cardiovasc Surg. 2004;127:376-84.

17. McCourtie AS, Merry HE, Wolf PS, FitzSullivan E, Keech JC, Farivar AS, et al. Synergistic protection in lung ischemia-reperfusion injury with calcineurin and thrombin inhibition. Ann Thorac Surg. 2010;89:1766-71

\section{Discussion}

Dr Joseph Zwischenberger (Lexington, $K y$ ). Dr Bayer, you are to be congratulated for such a technically challenging approach to orthotopic lung transplant as well as the use of nanoparticles. The issue with nanoparticles is that you have to do the pharmacokinetics, you have to match the delivery medium with the drug you are intending to deliver, and then you have to make sure it gets to the right place.

I am concerned about a couple things. First of all, you showed a distinct split between the dose delivery in the 4 rats that seemed to take on the drug and the 2 that did not. I would like to hear you comment, first of all, on how they were able to inhale the agent. You mentioned that they were inhaled, but you did not tell us how or the circumstances or how you would control the dosimetry.

The second question is, you only used 6 animals in each group, and because only 4 got the drug, we really did a study on 4 rats. I am concerned that we did not have a large enough N. Lastly, we are all judged on lung transplantation at 1-year and 3-year survivals, and yet this study only went 4 hours.

I would like to hear your responses to those, please.

Dr Bayer. To your first question about the delivery of the drug, in a pharmacokinetic study that had been done previously, we were able to show adequate delivery of the drug to the rats. One of the problems is that the rat is placed into a nose-only chamber and this is connected to an Aeroneb nebulizer (Aerogen, Galway, Ireland) where the medication gets aerosolized and the rat breathes spontaneously. Things that could affect the drug delivery are if the rat has rapid breathing or anxiety, there could be unequal delivery into the lungs; some of the drug could be deposited into the main airway and not go all the way into the lower airways; and if they have rapid breathing, the drug could be eliminated faster. I think in future studies we might need to test administering the drug while the rats are endotracheally intubated and mechanically ventilated and we might have a more uniform delivery of the drug.

Your question about the N, prior to the study, when we were doing our proposal, we had a power calculation done by our statistics department. They suggested that an $\mathrm{N}$ of 6 should be appropriate to see a treatment effect. We did not anticipate that 2 rats would have lower tacrolimus levels compared with the rest of them. Now, reviewing our results we might have needed a higher $\mathrm{N}$ in the beginning to show a beneficial effect of the medication.

Dr Zwischenberger. And the 4 hours?

Dr Bayer. We wanted to look at early changes after ischemiareperfusion injury. We know that within a few hours after reperfusion that there is already an abundant amount of release of inflammatory cytokines and influx of neutrophils, T-cells, and macrophages into the graft. Other studies that we looked at before the start of our experiments used a similar reperfusion time of 4 hours and were able to show an effect on the ischemia reperfusion injury with pretreatment of tacrolimus.

Dr Zwischenberger. So you have hit upon a very important point and that is that the delivery of nanoparticles is very dependent on how slowly and how deeply the recipient breathes and how it is delivered. I look forward to when you train your rats to breathe slow and deep.

Dr Frank D'Ovidio (New York, NY). I have a couple of questions. What was the preservation solution that you used for the lungs?

Dr Bayer. We did not preserve the lungs. We used fresh lung for our flow cytometry analysis, and then the lung was frozen for the rest of the analysis.

Dr D'Ovidio. No, I mean during the ischemic period of time. Did you flush the lungs?

Dr Bayer. When the lungs were harvested, we flushed them with the preservation solution Perfadex (Xvivo, Göteborg, Sweden), and then they were stored in an inflated state on ice.

Dr D'Ovidio. I probably missed it throughout the presentation. Why did you have to use lactose as a vehicle?

Dr Bayer. Lactose was chosen because it is well tolerated, easily absorbed, and it is thought to help with the absorption of the tacrolimus, which is by nature a lipophilic drug.

Dr D'Ovidio. Along that line, did you try a group of rats where you just used normal saline and see what the inflammatory response is from delivering lactose?

Dr Bayer. I'm sorry, could you please explain your question?

Dr D'Ovidio. Did you test the lactose per se versus a control group of normal saline?

Dr Bayer. No, we have not done that. That would be something we could include in a future study.

Dr D'Ovidio. I would suggest you do it, because a 3-hour ischemic time in a rat model historically would give much better $\mathrm{Po}_{2} \mathrm{~S}$, and I wonder if the lactose per se is giving you an inflammatory process. I would double-check for that. I worked with a model, and to get the model to work, we would have to implement 18 hours of cold ischemia to show the difference in $\mathrm{PO}_{2} \mathrm{~S}$. 